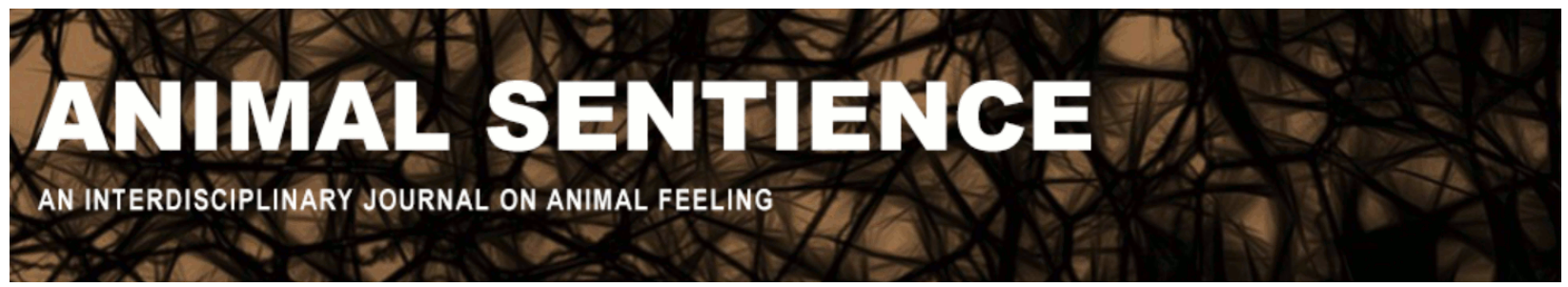

Fischer, Bob (2016) What if Klein \& Barron are right about insect sentience?. Animal Sentience 9(8)

DOI: $10.51291 / 2377-7478.1138$

Date of submission: 2016-08-06

Date of acceptance: 2016-08-10

(c)

This article has appeared in the journal Animal

Sentience, a peer-reviewed journal on animal

cognition and feeling. It has been made open access,

free for all, by WellBeing International and deposited

in the WBI Studies Repository. For more information,

please contact

wbisr-info@wellbeingintl.org.

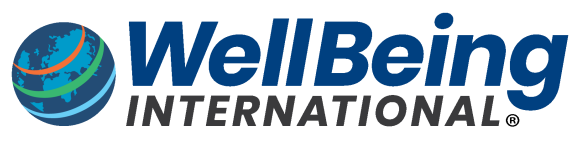

SOLUTIONS FOR PEOPLE, ANIMALS AND ENVIRONMENT 


\title{
What if Klein \& Barron are right about insect sentience?
}

Commentary on Klein \& Barron on Insect Experience

\author{
Bob Fischer \\ Department of Philosophy \\ Texas State University
}

\begin{abstract}
If Klein \& Barron are right, then insects may well be able to feel pain. If they can, then the standard approach to animal ethics generates some implausible results. Philosophers need to develop alternatives to this framework to avoid them.
\end{abstract}

Bob Fischer, assistant professor in the Department of Philosophy at Texas State University, works on animal ethics and the epistemology of modality, and is co-director the Society for the Study of Ethics and Animals. http://www.bobfischer.net

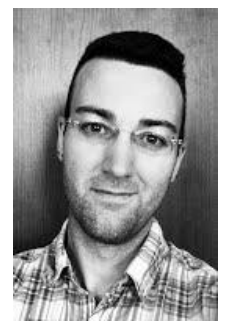

Some things matter morally; some things don't. On the former list, you'll find people, chickens, and lions; on the latter, dead leaves, banana peels, and gravel. When your actions might affect people, you should think about how they'll be affected; when your actions might affect dead leaves, you needn't.

Historically, we've put insects on the latter list. This isn't to say that we never think about how our actions might affect them, but just that insofar as we do, it's not for their own sake. Why shouldn't we let the bees die? Because agriculture would suffer (among many other things). Or, why shouldn't we let children tear the legs off spiders? Because they might thereby become cruel. On the standard view, bees and spiders matter, but not in and of themselves.

I doubt that this is quite right, but nor is it too far from the truth. We're guilty of many moral evils, a host of which involve nonhuman animals. Perhaps insects have some intrinsic moral importance, and so we ought to show more concern for them than we currently do. Still, I'm not inclined to draw moral parallels between, say, our use of insecticides and industrial animal agriculture. Even if insects matter, pigs matter much more. So were we ever to face a choice between harming pigs and harming insects, it's clear what we should choose.

Unfortunately, the dominant approach in animal ethics doesn't fit neatly with these truisms. My aim here is to explain why, and then to suggest a way forward. 
Recall our two lists: on the one hand, the things that matter morally; on the other, the things that don't. What's shared by the beings on the former that's lacking in the beings on the latter? A natural answer is: sentience. The beings on the former list have a perspective on the world; there is something that it's like to be each one of them. Moreover, things can go better and worse for them experientially - that is, they can feel pleasure and pain. If insects are sentient, we've got them on the wrong list.

To be clear, Klein \& Barron's (2016) argument for insect sentience doesn't commit them to saying insects can feel pain, and they're careful not to take a stand on that issue. Mere consciousness - what we might call minimal sentience - may be possible without the capacity to experience pain. However, the standard argument against insect pain is that the behavioral evidence isn't sufficient to attribute consciousness - we can explain what looks like pain behavior as the product of simple reflexes. (See, e.g., Wigglesworth 1980, Eisemann et al. 1984, Smith 1991, and Elwood 2011.) If Klein \& Barron are right, though, we have reasons to attribute states of awareness having nothing to do with apparent pain behavior. If that's right, then there should be a presumption in favor of taking that behavior at face value.

So let's assume, for the sake of argument, that insects are both conscious and can feel pain that is, they're fully rather than minimally sentient - and that they matter morally as a result. What follows? Well, consider the number of bugs killed by cars. Arnold van Vliet, a Dutch entomologist, came up with an estimate:

"In 2007, over 7 million cars [in the Netherlands] traveled about 200 billion kilometers. If we assume for simplicity that every month the average is the same for all cars, then 16.7 billion kilometers are traveled a month. In just the license plates, 3.3 billion bugs are killed per month. The front of the car is at least forty times as large as the surface of the plate. This means that cars hit around 133 billion insects every month. In half a year, that is 800 billion insects." 1

If the Dutch kill 800 billion insects every six months, then the mind boggles at the number across the globe. And if insects matter morally - and so we ought to factor them into our moral deliberations - then we've got some explaining to do. Even if insects are dramatically less important than we are, that difference may be offset by their sheer number. If each bug is morally important, can we justify non-essential driving? ${ }^{2}$

\footnotetext{
${ }^{1}$ http://www.treehugger.com/cars/trillions-of-insects-killed-by-cars-every-year-says-study.html

${ }^{2}$ Strictly speaking, we don't need the assumption that insects are sentient - or even that they're probably sentient - to get this problem going. Even if Klein \& Barron haven't shown we should assign a probability greater than .5 to insect sentience, we might think that they've raised the probability of that hypothesis. But now suppose that before reading Klein \& Barron, we were nearly certain that insects aren't sentient - we judged the probability to be around $.00001 \%$. Now, however, we take the probability to be a lot higher, though still extremely low - say, $1 \%$. When you consider the sheer number of insects, even a low estimate of the odds of sentience is going to generate high expected disutility from harming them. For more on insects and risk, see Fischer (2016).
} 
This problem has driven at least one philosopher to a fairly radical conclusion. Peter Carruthers (2007) is an advocate for higher-order theories of consciousness, so he doesn't think that insects are sentient. But he also doesn't think that sentience is what matters: instead, he has the (somewhat idiosyncratic) view that it's frustrated desires. We can set the disagreement aside here, however, since Carruthers argues that insects indeed have a belief/desire psychology, and it's clear that they don't always get what they want. Accordingly, he contends that "the challenge for ethical theory" is to reconcile - or reject one of - the following claims:

1. When people suffer, the basic ground for our sympathy and moral concern lies in their states of frustrated desire.

2. Invertebrates share with us a form of belief-desire psychology, and are capable of having their desires frustrated.

3. The sufferings of invertebrates make no direct moral claims on us.

4. The sufferings of some "higher" animals (paradigmatically dogs, cats, horses, and primates) do make direct moral claims on us (296-297, emphasis added).

It's easy to sympathize with the third claim, which Carruthers takes for granted. If we reject it, then we're at risk of saying that it's wrong to take two trips to the grocery store when you could take one. Given that that's off the table, we need another way out.

Carruthers doesn't think that all four claims can be reconciled, so he abandons (4). We should pause to appreciate the significance of this move. Carruthers thinks we should give up the idea that you shouldn't kick a dog in the ribs because it hurts the dog, independently of any consequences that injuring an animal might have for a human being (whether yourself or someone else). That's what it means to say that the sufferings of some "higher" animals don't make direct moral claims on us. And that is not a trivial conclusion.

Carruthers recognizes this, and so he tries to explain away the intuition in favor of holding onto (4). His proposal, which is developed at length in Carruthers (1992), is that we do have obligations regarding animals - including insects - but not to them. That is, they don't matter in and of themselves, but only for the reason outlined earlier: we shouldn't deform our characters, since doing so may have negative consequences for people; however, if we harm animals for insufficiently good reasons, that's exactly what we'll do. Moreover, the only reason we have obligations to infants (among others), and not just regarding them, is because the social contract isn't endorsable if we don't assume direct obligations to some beings who aren't themselves contractors. This isn't because the contract would mis-describe our children: on this view, morality is a system of rational agreements between agents, and infants aren't agents. Rather, it's because it would be irrational for us to endorse a contract that wasn't sustainable, as would be a contract that denied our children full moral consideration. But that, of course, is a long way of saying that they don't matter intrinsically, but instead because we care about them. 
This vision of our children is tough to swallow. It's also hard to stomach that the only reason it's wrong to kick your dog is because you might become a worse person as a result. But these are essential features of Carruthers's framework. Are there are any other options?

Here are four worth considering:

1. Give up sentience as the standard. We were wrong about the feature that's common among the beings on the former list. Of course, we can't go with Carruthers's proposal either, since it leads to the same set of problems. But perhaps we can find another candidate.

2. Adopt a graduated account of moral importance. Insects matter, but just barely. The more complex you are, the more you matter morally, where complexity maps roughly onto the phylogenetic scale.

3. Deny that insects have various interests. Perhaps insects are sentient, which means that they probably have an interest in avoiding pain. Still, they might not have an interest in continued existence, so killing them quickly might be OK.

4. Appeal to unforeseen consequences. Perhaps it's the case that if we were to drive less, things would actually be worse for insects. Perhaps our driving is hastening the sixth great extinction, which will take out enough insect predators to make things better for insects overall.

In a sense, this last option is the most attractive. We preserve the status quo, both practically and theoretically, but only because the empirical details just happen to break in our favor. To make this option plausible, however, we'd need evidence that the evidence details do break in our favor. Absent such evidence, caution is probably required, which means giving insects the benefit of the doubt. For now, then, we'll have to look elsewhere for a solution.

The third option, which denies that insects have certain interests, is perhaps the next most attractive. And it does seem plausible: even if insects are conscious, they probably aren't selfconscious, which severely restricts the kinds of interests they can have. Still, they probably have an interest in avoiding pain, and lots of insect deaths are probably painful - think, for instance, of the (relatively) slow death that an insect might experience after being exposed to a pesticide. If a host of our agricultural practices wound up being morally problematic, that would be a fairly dramatic result.

The second option appeals to a graduated account of moral importance. We're strikingly unlike beagles, which are strikingly unlike blowfish, which are strikingly unlike beetles. Surely those dissimilarities count for something.

Maybe so. There is, however, the so-called problem of marginal cases. A just-born infant is less sophisticated than a healthy adult pig, yet seems to matter more. Whatever the difference we 
identify - intelligence, a particular skill, or what have you - there seem to be cases where some nonhuman animals beat some humans in that respect. At risk of concluding that those humans matter less than those animals, philosophers tend to go in for the principle of equal consideration of interests, which says that the like interests of each being are of equal moral importance.

At this juncture, we come back to part of Carruthers's proposal: maybe the problem is using sentience as the standard. Perhaps it should be something else, like the capacity for rationality. Again, though, there are some humans that seem to lack that capacity - for example, the patient in a coma, or a person with congenital and severe cognitive disabilities. And if we just say that being human is what matters, we have to wonder why privileging that biological category is any less arbitrary than privileging others, like race or sex. What are we to do?

The truth, in short, is that I don't know. But since we need a way forward, I'll suggest the move that seems most promising to me. The empirical facts about what's best for insects may not break our way; giving up sentience comes at a high cost. Our best bet, therefore, may be to combine the other two strategies: on the one hand, deny that insects have various interests; on the other, appeal to a graduated account of moral importance.

Denying interests limits the ones with which animal and human interests compete, while the graduated account minimizes how much weight we give to the interests that remain. Suppose that dogs have an interest in continued existence, whereas bugs don't; suppose further that bug interests are relatively insignificant. In that case, perhaps we don't have to let fleas continue to bother a dog, but can instead try to exterminate them. Either option alone may not get that result: insects and dogs may share too many of the same interests, and even if dogs matter much more, the good for hundreds (or thousands) of bugs might outweigh the good for one dog. Together, though, these two strategies just might be successful.

My hope is that we can justify different interests based on the facts about various kinds of creatures, and then justify the graduated account in terms of the relative interests of the beings it ranks. If I have lots of basic and sophisticated interests, and a cockroach has only a few basic and no sophisticated interests, then it might not be surprising that I matter more. But it isn't clear whether these moves will work. Further empirical research on insects may show that they have much richer mental lives than we once thought, and so have correspondingly sophisticated interests. Likewise, further philosophical research on the graduated account needs to tackle the problem of marginal cases.

There's reason to be optimistic on both fronts. While it may turn out that we've underestimated the minds of insects, we're unlikely to find that they rival the minds of chickens, much less primates. Likewise, there has been renewed interest in the problem of marginal cases, and although it isn't yet clear how best to address it, a number of recent proposals are worth exploring - for example, Jaworska \& Tannenbaum (2014), Kagan (2016), and Lynch \& McLean (forthcoming) - even if they have problems as currently formulated. With some luck, then, we 
can develop a framework that helps us to think more clearly about the relative moral importance of all animals, whatever their species.

\section{References}

Carruthers, P. (1992) The animals issue: Moral theory in practice. Cambridge University Press.

Carruthers, P. (2007) Invertebrate minds: A challenge for ethical theory. Journal of Ethics 11.3: 275-297.

Eisemann, C.H., Jorgensen, W. K., Merritt, D. J., Rice, M. J., Cribb, B. W., Webb, P. D. and Zalucki, M. P. (1984) Do insects feel pain? A biological view. Experientia 40.2 164-167.

Elwood, R. W. (2011) Pain and suffering in invertebrates? ILAR 52.2: 175-184.

Fischer, B. (2016) Bugging the strict vegan. Journal of Agricultural \& Environmental Ethics 29.2: 255-263.

Jaworska, A. and Tannenbaum, J. (2014) Person-rearing relationships as a key to higher moral status. Ethics 124: 242-271.

Kagan, S. (2016) What's wrong with speciesism? Journal of Applied Philosophy 33.1: 1-21.

Klein, C. and Barron, A. B. (2016) Insects have the capacity for subjective experience. Animal Sentience 2016.100.

Lynch, T. and McLean, L. (forthcoming) How to do animal ethics. Journal of Agricultural \& Environmental Ethics.

Smith, J. A. (1991) A question of pain in invertebrates. ILAR 33.1-2: 25-31.

Wigglesworth, V. B. (1980) Do insects feel pain? Antenna 4: 8-9. 